\section{The chronology of the interna- tional response to Ebola in Western Africa: lights and shadows in a frame of conflicting position and figures}

\author{
Giuseppe Ippolito, Antonino Di Caro, \\ Maria Rosaria Capobianchi
}

National Institute for Infectious Diseases Lazzaro Spallanzani, Rome, Italy

"... one might say, the end of the first period, that of bewildering portents, and the beginning of another, relatively more trying, in which the perplexity of the early days gradually gave place to panic."

Albert Camus, The Plague, 1948

\section{Background}

The ongoing Ebola virus outbreak in western Africa illustrates the threat coming from emerging infectious diseases and is perceived by the public as a preeminent public health problem. ${ }^{1}$ An old disease, first reported in the Democratic Republic of Congo in 1976, determined an unprecedented number of cases. In western countries, Ebola has been perceived in 2014 as a global risk and the Time Magazine named The Ebola Fighters as persons of the year.

Peter M. Sandman and Jody Lanard, two internationally renowned experts on risk and crisis communication, published on December 2014 an analysis of Google Trends data showing increased Ebola public interest in the United States (US) of America starting from August and with a peak in October 2014, after the first case was diagnosed in the country. Evaluating the US Ebola experience the authors identified four main crisis communication errors (over-reassurance, over-confidence, proposal of unreasonable Ebola precautions, over-reaction) and provided specific recommendations for crisis management. ${ }^{2}$

A quantitative analysis of 3420 international publications indexed by Medline over a 39 years period evidenced an impressive increase of the number of papers published in the last year, with a 8-time increase in 2014 over 2013 (907 vs 108 papers), and a sharper increase in the first 100 days of 2015 (659 papers). Data extracted on 15 April 2015 are reported in Table 1. Of course, data across such a long period of time are not comparable, since the publication and indexing policy has heavily changed (but quite less in the last 5 years). However, the increase in 2014 remains impressive. Although some progress have been made, the increased number of publications has not been paralleled by a similar increase in the knowledge of pathogenesis, clinical management and prevention and control measures of the disease. The initial technical response to the outbreak has been poor and delayed and has been carried oud mostly by non-governmental organization already present in the field. Only after the increase in media attention and in scientific publication, the efforts of the national and international organization involved in the technical response have actually increased. Here we try to describe the chronology of the outbreak through the main general public breaking news that have characterized the outbreak.

\section{One year of heavy work: a per- sonal chronology}

According to personal experience, the chronology of the ongoing outbreak of Ebola virus Disease (EVD) started on Wednesday 19 March 2014 when in Guinea Conakry the health authorities reported at least 35 cases of an unknown disease characterized by diarrhea, vomiting, very high fever and in some cases bleeding occurred in the country. ${ }^{3}$ Most of the victims had been in contact with the deceased or had handled the bodies; the patients were isolated and samples shipped to Senegal and France to be tested. Actually, samples were delivered to Biosafety Level 4 (BSL4) laboratories in Lyon and Hamburg where the diagnosis of Ebola virus infection was confirmed.

On March 21, the EU DG DEVCO funded European Mobile Lab (EMLab) Consortium (http://www.emlab.eu/), that include the National Institute for Infectious Diseases L. Spallanzani (INMI), was alerted by WHO and we were immediately obliged to revise all the project plans of activity. In few days, the first EMLab was deployed to Guinea Conakry to assist the country in response to the Ebola outbreak, working under the umbrella of World Health Organization - Global Outbreak Alert and Response Network (WHO-GOARN). The first EMLab team, consisting of six members (2 from Munich, 2 from Hamburg including Stephan Günther as coordinator, 1 from Rome and 1 from Lyon) from three different EU countries (Germany, France and Italy), arrived safely in Conakry on March 27. On Saturday 29 , after a long and difficult journey, the mission reached Gueckedou, the epicenter of the outbreak in the forestry region of Guinea, to set up the first field laboratory in the local Ebola Treatment Center (ETC) managed by Medicins Sans Frontiers (MSF). Since March 2014 the INMI's daily activities and the personal life of colleagues and staff involved in pre-
Correspondence: Giuseppe Ippolito, National Institute for Infectious Diseases "Lazzaro Spallanzani", Via Portuense 292, 00149 Rome, Italy.

Tel.: +39.06.5517.0700

E-mail: giuseppe.ippolito@inmi.it

Received for publication: 18 April 2015. Accepted for publication: 20 April 2015.

This work is licensed under a Creative Commons Attribution NonCommercial 3.0 License (CC BYNC 3.0).

(C) Copyright G. Ippolito et al., 2015

Licensee PAGEPress, Italy

Infectious Disease Reports 2015; 7:5957

doi:10.4081/idr.2015.5957

paredness and response were tzunamed, and now, one year later Ebola continues to be the most relevant and challenging duty. Our involvement in the outbreak response has not been limited to the laboratory team.

In August 2014, answering a WHO request, INMI sent an experienced clinician to Nigeria, in order to provide clinical expertise and technical support for the management of the special Ebola isolation unit in Lagos. In October 2014, the Italian Ministry of Foreign Affairs appointed as Chief and Project Manager of the Italian intervention in Sierra Leone an experienced project manager from INMI. On November 25, a 50-year old male diagnosed with EBV in Sierra Leone was admitted to INMI. During his stay, which lasted 5 weeks, he received different experimental treatments and needed intensive care support for 7 days. The patient fully recovered and was discharged on January 2, 2015. On December 12, 2014, INMI activated a new laboratory (an advanced, not a standard mobile lab) in Goderich Sierra Leone. The lab, located in the premises of the new treatment center managed by the Italian NG0 Emergency, was established in the framework of the activities funded bu Italian Ministry of Foreign Affairs in Sierra Leone and with the economic contribution, logistics and support by the Italian NGO Emergency. In February 2015, an IPC expert went to Sierra Leone, to support the re-opening of a local general hospital in the context of the EVD outbreak. Since 1995, when INMI was identified by the Italian Ministry of Health as the national reference centre for viral hemorrhagic fevers, our Institute has been working hardly to develop a preparedness and response model, continuously refined and reassessed during all recent events involving emerging or re-emerging highly infectious diseases (HIDs). ${ }^{4}$ The INMI model is based on: $i)$ the availability of high isolation units and of high containment laboratories (BSL3 and 4); ii) long experience 
on field interventions for HIDs in Italy and in third countries; iii) integration among clinical, epidemiological and pre-clinical research teams.

\section{The official chronology}

December 2013: the first case of mysterious deaths occurred in Guinea Conakry (at Meliandou, Guéckédou Prefecture), but remained undiagnosed.

March 22, 2014: after the results of tests performed in two European BSL4 laboratories, the Ministry of Health $(\mathrm{MoH})$ of Guinea declared the outbreak as Ebola. In the following weeks, EVD spread to the neighboring countries Liberia and Sierra Leone, where the infection had a widespread and intense transmission.

March 23, 2014: WHO posted on website the announcement of a rapidly evolving outbreak of Ebola in the nation's forestry region and in the capital city, Conakry.

June 2014: the news reported that the Guinean government criticized WHO for publishing conflicting figures.

July 7, 2014: MSF published a report underlining limitations and deficiencies of the international aid response to crises. ${ }^{5}$

August 7, 2014: the Spanish government decided to repatriate from Liberia to Madrid a Spanish missionary that acquire EVD while working as health care worker at the Catholic Hospital in Monrovia.

August 8, 2014: the Health Regulations Emergency Committee (HREC) provided unanimous advice to the WHO Director General (DG) to address the EVD outbreak in accordance with International Health Regulations (IHR 2005). The advise was based on the following criteria: EVD outbreak in West Africa constitutes an extraordinary event and a public health risk to other States; the possible consequences of further international spread are particularly serious in view of the virulence of the virus, the intensive community and health facility transmission patterns, and the weak health systems in the currently affected and most at-risk countries; a coordinated international response is deemed essential to stop and reverse the international spread of Ebola. ${ }^{6}$

August 8, 2014: the WHO-DG promptly declared EVD outbreak a Public Health Emergency of International Concern (PHEIC).

August 15, 2014: MSF criticized the WHO for underestimating the problem, declared the international effort to contain the outbreak dangerously inadequate and called for an immediate and massive mobilization of human and technical resources to the affected region. ${ }^{7}$

August 12, 2014: David Nabarro was appointed Senior UN Coordinator on Ebola, to provide strategic and policy direction for an enhanced international response, and galvanize essential support for affected communities and countries. On September 23, he will be appointed Special Envoy on Ebola, continuing to serve also as Special Representative of the Secretary-General for Food Security and Nutrition and Coordinator of the Movement for Scaling Up Nutrition (SUN) ${ }^{8}$

September 18, 2014: the UN Security Council approved the resolution n. 2177. For the second time in his history, the UN Security council issued a resolution on a disease. The resolution was justified by the following arguments: the severity of the health crisis requires unprecedented action and response at international level; the request by the leaders of affected countries to the UN to coordinate a global response; the need for urgent measures to save human lives, the livelihood of affected areas, peace and global security.

September 19, 2014: after the unanimous adoption of General Assembly resolution 69/1, and the adoption of Security Council resolution 2177/2014 the UN Secretary General Ban Ki-Moon established the UN Mission for Ebola Emergency Response (UNMEER), the firstever UN emergency health mission. The first time that UN has taken direct control on management and control efforts for a health crisis. Anthony Banbury was appointed as Special Representative for UNMEER.

September 30, 2014: the first case of Ebola diagnosed in the United States in a man who traveled to Dallas, Texas from Liberia. The patient was asymptomatic when leaving Liberia, developed symptoms approximately four days after arriving in the United States and was admitted to Texas Presbyterian Hospital. ${ }^{9}$

October 6, 2014: the first Ebola transmission case outside of Africa, in a Spanish nurse who was caring for the Ebola infected missionary repatriated on August 7.. ${ }^{10}$

October 10, 2014: a nurse working at Texas Presbyterian Hospital, who provided care for the EVD patient resulted positive.

October 15, 2014: a second nurse who provided care for the same patient tested positive.

October 17, 2014: the associated press (AP) published that a draft of a WHO internal document admitted relevant problems in response to Ebola. ${ }^{11}$ The document analyzed critical aspects such as incompetent staff, lack of information to the WHO DG, bureaucracy and aids blockage by administrative hurdles, politically motivated appointments of heads of WHO country offices in Africa, lack of assistance by WHO office in Guinea to help get visas for an experts Ebola team. In June, Bruce Aylward, in charge for polio eradication, alerted the WHODG about the serious concerns being raised about WHO's leadership in West Africa. In an e-mail Aylward reported that some of the
Table 1. Time trend in number of documents on Ebola indexed in Medline (2015 until 15 April).

\begin{tabular}{lc} 
Year & Number of publications \\
\hline 2010 & 106 \\
2011 & 153 \\
\hline 2012 & 145 \\
2013 & 108 \\
\hline 2014 & 907 \\
2015 & 659 \\
\hline
\end{tabular}

Medline totals were calculated through PubMed's interface. Available at http:/www.ncbi.nlm.nih.gov/pubmed/?term=ebola.

agency's partners - including national health agencies and charities - believed that the agency was compromising rather than aiding the response to Ebola and that none of the news about WHO's performance is good.

In a comment to the information published by AP, Peter Piot stated that WHO acted far too slowly, largely because of its African office. It's the regional office in Africa that's the frontline ... and they didn't do anything. That office is really not competent.

January 3, 2015: Ismail Ould Cheikh Ahmed succeeded Anthony Banbury as Special Representative for UNMEER with the mandate to continue to provide the operational framework and coordination to: stop the Ebola outbreak; treat the infected; ensure essential services; preserve stability; prevent the spread to countries currently unaffected.

January 25, 2015: the WHO Executive Board unanimously approved, after 4 days of discussion, the resolution Ebola: ending the current outbreak, strengthening global preparedness, and ensuring WHO capacity to prepare for and respond to future large-scale outbreaks and emergencies with health consequences. In order to improve WHO's ability to manage global health emergencies, the resolution recommends: i) evaluating pooled funds for global health research and development for sustainable solutions to future health crises and outbreaks; ii) the delinkage of the cost of new research and development from the prices of medicines, vaccines, and other diagnostics for Ebola to ensure their sustained accessibility, affordability, availability, and access to treatment; iii WHO reforms including contingency fund for outbreak emergencies.

February 4, 2015: WHO DG appointed the assistant DG Bruce Aylward as Special Representative for the Ebola Response.

February 3, 2015: WHO announced the establishment of an independent commission to assess WHO's widely criticized response to the epidemic, after the UN agency admitted last month it had been caught napping on Ebola and pledged reforms to avoid similar mistakes in the future. The assessment com- 
mission will present an interim report in May and conduct a full review of WHO's handling of the epidemic to guide future work in emergencies and outbreaks.

March 10, 2015: WHO-DG appointed six health experts for the assessment of its oft-criticized response to the Ebola outbreak in West Africa [1-Barbara Stocking, former CEO of Oxfam GB, now president of Murray Edwards College (panel leader); 2-Carmencita AlbertoBanatin, consultant for the response to Typhoon Haiyan in southern Philippines; 3-Julio Frenk, dean at the Harvard School of Public Health in Boston; 4-Ilona Kickbusch, director of the Global Health Program at the Institute of International and Development Studies in Geneva; 5-JeanJacques Muyembe-Tamfun adviser to WHO's IHR Emergency Committee on Ebola; 6-Faisal Shuaib, head of Nigeria's National Ebola Emergency Operations Center].

March 20, 2015: the AP published six WHO internal documents mailed between top officials of the Agency evidencing that senior directors were early informed of the situation and held off on declaring a global emergency. According to the documents, in early June, one WHO's director viewed the possibility of an emergency declaration as a last resort. As reported by Associate Press in an e-mail sent on March 17, WHO said: People often confuse the declaration of a Public Health Emergency of International Concern with our operational response. It is very different. WHO mounted a strong operational response a year ago when we were notified the outbreak was Ebola.

The article by AP report also that Dr. Sylvie Briand, head of the pandemic and epidemic diseases department at WHO, acknowledged that her agency made wrong decisions but said postponing the alert made sense at the time because it could have had catastrophic economic consequences. In a mail sent to WHODG on June 10, an assistant DG and others sent a memo to WHO say that declaring an international emergency or even convening an emergency committee to discuss the issue could be seen as a hostile act. ${ }^{12}$

March 23, 2015: MSF publish a glossy and full of pictures report with the non-governmental organization' (NGO) critical analysis of the global Ebola response one year into the outbreak. ${ }^{13}$

April 10, 2015: during the 5th meeting of the IHR Emergency Committee regarding the Ebola outbreak in West Africa the WHO Director-General declared that the Ebola outbreak in Guinea, Liberia and Sierra Leone continues to constitute a Public Health Emergency of International Concern. So far, we have reported facts that we believe are relevant. However, this is a personal view. Several chronologies with more detail on the events and comments on the role of the different players involved in the outbreak have been published or posted in the net.

\section{Perspectives}

In the above chronology, only the actions of the WHO and of special programs established by the secretary of UNs and the main criticisms to WHO have been reported.

Many similar decisions, driven more by politics than based on evidence and on a clear vision of the response model, have been adopted by the European Commission.

Detailed explanations and further discussion on the lesson learned are needed in order to fairly evaluate the appropriateness of the response. Most of the UN agencies have probably developed competing programs for Ebola preparedness and response with the result of a far from coordinated response. Besides supranational agency there are active at continental level established individual uncoordinated policies.

The effect is a plethora of bodies/authorities with a real risk of duplication of functions and costs, and the difficulty to have a well-defined chain of command and control.

The response to the epidemic can be only technical, organized, coordinated and managed with leadership, avoiding confusion of roles between the public institutions and nongovernmental organizations. Otherwise, the effect of action is at least hampered and sometimes worse than inaction.

The analysis of the role and responsibilities of the various UN agencies, Institutions and NGOs involved in the outbreak, with their strengths and weaknesses, is outside the goal of this paper and as well as of our skills, but the epidemic is not over yet and the rebound of responsibilities is misplaced.

\section{Some final remarks}

The communication strategy must be improved, and the impact of information disseminated to the public must be carefully evaluated for the risk of loss of trust and confidence in international organizations.

All the NGO who toke part to the outbreak response must be acknowledged, and in particular MSF, who has definitely arrived first on the field and has done an extraordinary job with an unparalleled logistics, playing a pivotal role in the management of the event and having a remarkable ability to communicate their activities and involve the media.

The successes and the missed opportunities of WHO and other international organizations, with special focus on the management of previous epidemics in the past decade and the need of reform have been extensively analyzed in more than two decades of published papers and documents. ${ }^{14-17}$ However, there is still a long way to go if we want to improve the current situation and return to a supranational public organization as WHO, the fully recognized leading role in outbreak response. A new balance between the role to be assumed in outbreak response by international institutions and NGO is really needed.

The role of NGOs, as debated in a recent commentary based on the experience of the response to HIV/AIDS, need to be re-evaluated by area of expertise and codes of conduct to be more appropriately integrated to a well-coordinated international outbreak response activity. ${ }^{18}$ NGOs are useful and essential to strengthen local services, notwithstanding the establishment of codes of conduct for NGOs are recommended by many organizations..$^{19,20}$ For the future, it is important to make more effective decisions through the use of proven strategic thinking and decision making techniques. New strategies are needed to account for these lessons learned in order to appropriately respond to future outbreaks.

\section{References}

1. WHO. Ebola Situation Report - 25 March 2015. Available from: http://apps.who. int/ebola/current-situation/ebola-situation-report-25-march-2015

2. Sandman PN, Lanard J. Commentary: when the next shoe drops. Ebola crisis communication lessons from october. 2014. Available from: http://www.cidrap.umn.edu/news-perspective/2014/12/commentary-when-nextshoe-drops-ebola-crisis-communicationlessons-october

3. Reuters. Mystery hemorrhagic fever kills 23 in Guinea. 19 March 2014. Available from: http://www.standardmedia.co. ke/health/article/2000107329/mysteryhemorrhagic-fever-kills-23-in-guinea.

4. Di Caro A, Puro V, Fusco FM, et al. The added value of long-lasting preparedness for the management of a patient with Ebola. Eur J Intern Med 2015 Mar 26. [Epub ahead of print].

5. Médecins Sans Frontières. Where is everyone? 7 July 2014. Available from: http://www.msf.org/sites/msf.org/files/msfwhereiseveryone_-def-lr_-_july.pdf

6. WHO. Statement on the 1st meeting of the IHR Emergency Committee on the 2014 Ebola outbreak in West Africa. Available from: http://who.int/mediacentre/news/statements/2014/ebola-20140808/en

7. Philips M, Markham A. Ebola: a failure of international collective action. Lancet 2014; 384:1181.

8. United Nations. Special Envoy on Ebola. Available from: https://ebolaresponse. 
un.org/special-envoy-ebola

9. Centers for Disease Control and Prevention. Cases of ebola diagnosed in the United States. Available from: http://www.cdc.gov/vhf/ebola/outbreaks/20 14-west-africa/united-states-importedcase.html

10. Lópaz MA, Amela C, Ordobas M, et al. First secondary case of Ebola outside Africa: epidemiological characteristics and contact monitoring, Spain, September to November 2014. Euro Surveill 2015;20:pii21003.

11. TheStar.com. Ebola response badly fumbled, WHO admits. Available from: http:/www.thestar.com/news/world/2014/1 0/17/ebola_response_badly_fumbled_who admits.htm

12. Cheng M, Satter R. Emails: UN health agency resisted declaring Ebola emergency. Available from: http://bigstory.ap.org/article/2489c78bff864 63589b41f3faaea5ab2/emails-un-healthagency-resisted-declaring-ebola-emergency

13. Médecins Sans Frontières. Pushed to the limit and beyond. A year into the largest ever Ebola outbreak. Available from: http://www.msf.org/article/ebola-pushedlimit-and-beyond

14. Godlee F. The World Health Organisation: WHO in crisis. BMJ 1994;309:1424.

15. Sandman PM, Lanard J. The fake pandemic charge goes mainstream and WHO's credibility nosedives. June 29, 2010. Available from: http://www.psandman.com/col/WHO-credibility.htm
16. WHO. Sixty-Fifth World Health Assembly 2012. Decisions and list of resolutions. Available from: http://apps.who.int/gb/ ebwha/pdf_files/WHA65/A65_DIV3-en.pdf

17. Sridhar D, Gostin LO. Reforming the World Health Organisation. JAMA 2011;305:15856.

18. Pfeiffer J, Robinson J, Hagopian A, et al. The end of AIDS and the NGO Code of Conduct. Lancet 2014;384:639-40.

19. The Paris Declaration on Aid Effectiveness and the Accra Agenda for Action. 2008. Available from: http://www.oecd.org/dac /effectiveness/34428351.pdf

20. Pfeiffer J, Johnson W, Fort M, et al. Strengthening health systems in poor countries: a code of conduct for nongovernmental organizations. Am J Public Health 2008;98:2134-40. 